\title{
Adult T-cell leukemia/lymphoma can be indistinguishable from other more common T-cell lymphomas. The University of Miami experience with a large cohort of cases
}

\author{
Mahsa Khanlari ${ }^{1}$ - Juan Carlos Ramos ${ }^{2} \cdot$ Sandra Patricia Sanchez $^{1} \cdot$ Jeong Hee Cho-Vega ${ }^{3}$. Alexandra Amador ${ }^{1}$. \\ German Campuzano-Zuluaga ${ }^{1} \cdot$ Francisco Vega $\mathbb{D}^{1,2} \cdot$ Jennifer R. Chapman ${ }^{1}$
}

Received: 19 July 2017 / Revised: 13 November 2017 / Accepted: 23 January 2018 / Published online: 15 February 2018

(c) United States \& Canadian Academy of Pathology 2018

\begin{abstract}
Adult T-cell leukemia/lymphoma, an aggressive T-cell neoplasm, is causally linked to human T-cell lymphotropic virus type 1 and based on this association has a distinct geographic distribution. In our United States-based practice, whose population is enriched for immigrants from human T-cell lymphotropic virus type 1 endemic areas, we have identified that a subset of adult T-cell leukemia/lymphoma, in the absence of human T-cell lymphotropic virus type 1 identification, are indistinguishable from other more common T-cell neoplasms. We retrospectively gathered serology results for antihuman T-cell lymphotropic virus type 1/2 antibody in patients diagnosed with T-cell neoplasms at our institution. A total of 220 human T-cell lymphotropic virus type 1/2 positive patients with T-cell neoplasms were identified; 199 (91\%) were correctly classified as adult T-cell leukemia/lymphoma or provisionally as peripheral T-cell lymphoma (serology testing pending). Twenty-one cases (9\%) were initially misclassified, including the following: 13 presenting with skin $+/-$ peripheral blood involvement and misclassified as mycosis fungoides/Sezary syndrome; 7 with lymphomatous disease, absence of leukemic involvement, and diffuse CD30 expression, misclassified as ALK- negative anaplastic large-cell lymphoma; 1 thought to represent T-prolymphocytic leukemia with TCL-1 gene rearrangement and diffuse marrow involvement. We also present an example of adult T-cell leukemia/lymphoma, which mimicked lymphoepithelioid variant of peripheral T-cell lymphoma also with diffuse marrow involvement. A subset of adult T-cell leukemia/lymphoma can closely mimic a variety of other more common T-cell neoplasms. Due to its extreme clinicopathologic heterogeneity, identification of adult T-cell leukemia/lymphoma requires a high level of suspicion based on patient demographic alone, which should prompt anti-human T-cell lymphotropic virus type 1/2 serology testing in all T-cell neoplasms developing in patients of appropriate demographic. Absence of high level of suspicion, adult T-cell leukemia/lymphoma is easily misclassified.
\end{abstract}

Jennifer R. Chapman

jchapman@med.miami.edu

1 Department of Pathology, Division of Hematopathology, University of Miami, Sylvester Comprehensive Cancer Center, and Jackson Memorial Hospitals, Miami, FL, USA

2 Department of Medicine, Division of Hematology, University of Miami, Sylvester Comprehensive Cancer Center, and Jackson Memorial Hospitals, Miami, FL, USA

3 Department of Pathology, Division of Dermatopathology, University of Miami, Sylvester Comprehensive Cancer Center, and Jackson Memorial Hospitals, Miami, FL, USA

\section{Introduction}

Adult T-cell leukemia/lymphoma is an aggressive T-cell neoplasm arising from post-thymic regulatory T-cells and caused by the oncoretrovirus human T-cell leukemia virus type 1 , the first retrovirus proven to cause human malignancy. Development of adult T-cell leukemia/lymphoma in a subset of human T-cell leukemia virus type 1 seropositive patients is associated with unique clinical syndromes, a feature that allowed adult T-cell leukemia/lymphoma to be recognized as a distinct neoplasm before the causative agent was identified [1].

Human T-cell leukemia virus type 1 infection is endemic in several regions of the world, including southwestern Japan, mainly the islands of Kyushu and Shikoku, the Caribbean islands, parts of Central Africa, and regions in 
South America, Middle East (Iran), Papua New Guinea, Solomon Islands, and Romania. Viral transmission requires the presence of living human T-cell leukemia virus type 1infected cells and is typically acquired in infancy or childhood in endemic areas via transmission through breast milk, or is sexually transmitted. Development of adult T-cell leukemia/lymphoma in human T-cell leukemia virus type 1 carriers follow a distinctive geographic distribution that mirrors that of high prevalence of human T-cell leukemia virus type 1 [2]. A long latency period is required between human T-cell leukemia virus type 1 infection and development of lymphoma, which occurs in only a small subset of carriers with a cumulative lifetime risk of 2.5-5\% [3]. For these reasons, adult T-cell leukemia/lymphoma is generally a lymphoma of adults and is rare, particularly in nonhuman T-cell leukemia virus type 1 endemic areas of the world. However, the clinical presentation and histopathologic findings in patients with adult T-cell leukemia/lymphoma are incredibly variable and can be nonspecific in a subset of cases, making the appropriate identification of some adult T-cell leukemia/lymphomas difficult, particularly in non-endemic areas.

Adult T-cell leukemia/lymphoma can present in a variety of forms with varying degrees of leukemic and/or lymphomatous involvement. The clinical syndrome with which adult T-cell leukemia/lymphoma presents in a given patient is organized according to the Shimoyama classification as: acute $(60 \%)$, lymphomatous $(20 \%)$, chronic $(15 \%)$ or smoldering (5\%) [3]. Acute and chronic type presentations of adult T-cell leukemia/lymphoma are distinct among T-cell neoplasms, typically characterized by leukemic involvement, hepatosplenomegaly and hypercalcemia (acute form), making these presentations of adult T-cell leukemia/lymphoma relatively recognizable. Smoldering and lymphomatous presentations, however, often lack leukocytosis, lymphocytosis, hypercalcemia and hepatosplenomegaly (smoldering), making recognition of these forms of adult T-cell leukemia/lymphoma more difficult. Interestingly, in the Western world, not only is the incidence of adult T-cell leukemia/lymphoma low, but also the lymphomatous form is more common than other presentations, further complicating adult T-cell leukemia/lymphoma identification [4]. Additionally, a purely cutaneous type of adult T-cell leukemia/lymphoma that resembles mycosis fungoides has also been described [5]. This cutaneous type of adult T-cell leukemia/lymphoma has been reported to present with erythematopapular and/ or tumoral cutaneous lesions and could be regarded as a fifth, albeit uncommon, form of adult T-cell leukemia/lymphoma [5]. Patients presenting with one form of adult T-cell leukemia/lymphoma often transition to other forms during disease course, a feature that may unmask previously unidentified adult T-cell leukemia/lymphoma. Survival is dismal regardless of clinical subtype ranging from less than 1 year (acute and lymphomatous forms) to $\sim 2$ years (smoldering and chronic). Virtually, all patients have stage IV disease at presentation, making Ann Arbor staging prognostically irrelevant.

Compounding the difficulty of variability of clinical presentation, adult T-cell leukemia/lymphoma is also characterized by considerable histopathologic heterogeneity. Although the prototypical adult T-cell leukemia/lymphoma cell is the cytologically atypical lymphocyte present in leukemic phase with hyperchromatic nuclear chromatin and deeply lobulated nuclear contours (so-called flower cell), this morphology is common only to the acute form and is often absent in other forms. In chronic adult T-cell leukemia/lymphoma, for example, circulating lymphoma cells, if identifiable, are less cytologically atypical in appearance having subtle nuclear membrane irregularities. Lymphomatous and smoldering types may have no detectable leukemic involvement. Adult T-cell leukemia/lymphoma cells can range from small, mature appearing lymphoid cells with minimal cytologic atypia to large, pleomorphic cells with anaplastic features. They can have hallmark features, mimicking anaplastic large-cell lymphoma, and can also mimic Reed-Stenberg/Hodgkin cells. Alternatively, this lymphoma can be composed of small pleomorphic lymphoma cells and contain Hodgkin-like presumably reactive B-cells, CD30 and CD15 positive, and often Epstein-Barr virus encoded RNA (EBER) positive, thus mimicking classical Hodgkin lymphoma or angioimmunoblastic T-cell lymphoma.

Although adult T-cell leukemia/lymphoma often has a relatively specific immunophenotype including preserved expression of pan-T-cell markers (CD2, CD3, CD4, CD5) with strong coexpression of interleukin-2 receptor (IL-2R, also known as CD25) and frequent coexpression of FoxP3 with loss of $\mathrm{CD} 7$, this phenotype is not entirely sensitive or specific for adult T-cell leukemia/lymphoma [6-8]. For example, a subset of adult T-cell leukemia/lymphoma is negative for CD25 [9]. Similarly, FoxP3 is reportedly positive in most, but not all, adult T-cell leukemia/lymphoma cases, and expression of this protein is also reported in a variety of other T-cell neoplasms [10]. Adult T-cell leukemia/lymphoma can also express the chemokine receptor 4 (CCR4), particularly in the context of cutaneous involvement [11, 12]. A subset of adult T-cell leukemia/ lymphomas also express strong and diffuse CD30, particularly the lymphomatous form [13].

Although virtually all adult T-cell leukemia/lymphomas have complex cytogenetic abnormalities, due in large part to the deleterious effects of viral-encoded TAX, there are no recurrent molecular or cytogenetic abnormalities useful in identification of this lymphoma. Therefore, at this time, aside from identification of integrated human T-cell leukemia virus type $1 \mathrm{in}$ isolated lymphoma cells or anti- human 
T-cell leukemia virus type $1 / 2$ antibodies in patient's serum as an imperfect surrogate, there are no specific clinical, morphologic, immunophenotypic or molecular genetic features that define adult T-cell leukemia/lymphoma. Given the variability of clinical presentation and histopathologic features, the lack of specific molecular genetic features and the low incidence of human T-cell leukemia virus in USbased populations, recognition of a subset of adult T-cell leukemia/lymphoma (particularly lymphomatous and smoldering/cutaneous) can be problematic.

Our clinical practice is based in Miami-Dade County. As such, our patient demographic includes predominantly Miami-Dade county residents and is enriched for immigrants from the Caribbean basin and South America, where human T-cell leukemia virus type 1 is endemic. Additionally, we receive patient material and patients themselves in consultation from neighboring regions where adult $\mathrm{T}$-cell leukemia/lymphoma is prevalent. On the basis of our patient demographic, our Hematopathology practice has a high level of suspicion for adult T-cell leukemia/lymphoma when interpreting T-cell neoplasms in general. Despite this high index of suspicion and our relative familiarity with adult T-cell leukemia/lymphoma, we identified retrospectively that $9 \%$ of our cases were initially misclassified as other more common T-cell neoplasms. These cases were reclassified after either performance of anti-human T-cell leukemia virus type $1 / 2$ serology testing based on patient demographic alone or after transformation from an initially lymphomatous or smoldering neoplasm to one that became leukemic, prompting testing for anti-human T-cell leukemia virus type $1 / 2$ antibody. The purpose of this manuscript is to describe these initially misinterpreted cases, and in doing so to highlight the extreme histopathologic and clinical variability of adult T-cell leukemia/lymphoma.

\section{Materials and Methods}

\section{Case selection}

We retrospectively searched our pathology and clinical databases (2006-2016) for patients who had both a diagnosis of any T-cell neoplasm and anti- human T-cell leukemia virus type $1 / 2$ antibody detected in serum. Patients with T-cell neoplasm and anti-human T-cell leukemia virus type $1 / 2$ antibody were defined as having adult T-cell leukemia/lymphoma. Inclusion criteria also specified that diagnostic material be reviewed and patients treated at our institution. The pathology reports and clinical records of identified patients were reviewed. Cases initially classified histopathologically as adult T-cell leukemia/lymphoma or provisionally as peripheral $\mathrm{T}$-cell lymphoma, not otherwise specified with anti-human T-cell leukemia virus type
$1 / 2$ serology testing in progress at the time of initial diagnosis were considered appropriately classified and were not reviewed further. For the purpose of this report, those cases initially misclassified as T-cell neoplasm other than adult T-cell leukemia/lymphoma or peripheral T-cell lymphoma, not otherwise specified were selected for in-depth review. Diagnostic biopsy material in this set of cases was reviewed by two hematopathologists (JC, FV) and extensive review of medical records was performed. During the composition of this manuscript, we identified an additional case of adult T-cell leukemia/lymphoma that was correctly identified based on clinical presentation and patient demographic, but was striking its histopathologic mimicry of lymphoepithelioid variant of peripheral T-cell lymphoma, not otherwise specified with extensive marrow involvement. This case is added to this review in order to expand the documented morphologic spectrum in adult T-cell leukemia/lymphoma.

\section{Immunohistochemical studies}

A variable panel of immunohistochemistry and in situ hybridization assays was performed in each case based on the interpreting pathologist's differential diagnosis at the time of initial case review. CD25 was performed in a subset of cases and most commonly in retrospect. All immunohistochemistry and in situ hybridization assays were performed on diagnostic patient tissue available in the form of formalin-fixed, paraffin-embedded tissue blocks using Leica BOND III automated instruments in the University of Miami Department of Pathology's clinical immunohistochemistry laboratory. Conditions for individual immunohistochemistry or in situ hybridization assays varied according to antibody or probe used and were determined by standard optimization and validation procedures. Antibody clones used included CD20, CD3, CD5, CD7, CD4, CD8, CD2, CD25, CD30 and ALK-1 (all clones from Leica Biosystems Ltd. Newcastle, UK). Epstein-Barr Virus detection by in situ hybridization was performed in a subset of cases using an in situ hybridization probe aimed at detecting EBV-encoded RNA (Leica Biosystems Ltd. Newcastle, UK).

\section{Polymerase chain reaction analysis for detection of human T-cell leukemia virus type 1-encoded DNA and Touchdown polymerase chain reaction assays}

Polymerase chain reaction analysis for detection of human T-cell leukemia virus type 1-encoded DNA was performed in isolated peripheral blood mononuclear cells and/or tumor tissue extracted from formalin-fixed paraffin-embedded tissue sections. Genomic DNA templates were extracted from $5 \times 10^{6}$ cells using E.Z.N.A. ${ }^{\circledR}$ Tissue DNA Kit from Omega Bio-tek, Inc. (Norcross, GA). Primers for 
polymerase chain reaction were synthesized by Invitrogen (Carlsbad, CA). A concentration of $100 \mathrm{ng}$ of DNA templates were subjected to polymerase chain reaction amplification using REDTaq ${ }^{\circledR}$ ReadyMix ${ }^{\mathrm{TM}}$ from Sigma-Aldrich (St. Louis, MO) and primers with the following conditions: 1 cycle at $94{ }^{\circ} \mathrm{C}$ for $5 \mathrm{~min} ; 35$ cycles at $94{ }^{\circ} \mathrm{C}$ for $10 \mathrm{~s}, 58^{\circ} \mathrm{C}$ for $20 \mathrm{~s}$, and $72{ }^{\circ} \mathrm{C}$ for $1 \mathrm{~min}$; and 1 cycle at $72{ }^{\circ} \mathrm{C}$ for $5 \mathrm{~min}$. The following primers pairs were used: GAPDH $5^{\prime}$ CTCTCTGCTCCTCCTGTTCG-3', 5'-ACGACCAAATCC GTTGACTC-3'; HTLV-1 POL 5'-GCCTGGAGAGTA CTACCCCA-3', 5'-GTTTTCGGACACAGGCAACC-3'; HTLV-1 Env 5'-CTGTTCCCACGCTAGGATCC-3'; 5'AGGAGATCAAGGCCTCGTCT-3'; HTLV-1 GAG 5'AGTTTGACCCCACTGCCAAA-3', 5'-AGGATAGAGG CCCAGGAAGG-3'; HTLV-1 Tax 5'-TTATCAGCCCACTTCCCAGG-3', 5'-GAGCCGATAACGCGTCCATC$3^{\prime}$. Amplicons were resolved in $1 \%$ agarose/TBE gel, stained in $0.5 \mu \mathrm{g} / \mathrm{ml}$ ethidium bromide and visualized under UV light.

In order to minimize nonspecific polymerase chain reaction products, Touchdown polymerase chain reaction (TD-PCR) using Sigma's REDTaq ReadyMix was used in selected samples. Briefly, 20-50 ng of DNA (depending on sample yield) were initially denatured at $94^{\circ} \mathrm{C}$ for $5 \mathrm{~min}$, then 20 cycles at $94{ }^{\circ} \mathrm{C}$ for $15 \mathrm{~s}, 72^{\circ} \mathrm{C}-56^{\circ} \mathrm{C}$ for $30 \mathrm{~s}$, and $72^{\circ} \mathrm{C}$ for $60 \mathrm{~s}$. Mixtures were then subjected to another 30 cycles of $94^{\circ} \mathrm{C}$ for $15 \mathrm{~s}, 56^{\circ} \mathrm{C}$ for $30 \mathrm{~s}$, and $72^{\circ} \mathrm{C}$ for $60 \mathrm{~s}$. Final extension was for $5 \mathrm{~min}$ at $72{ }^{\circ} \mathrm{C}$. PCR products were loaded onto a $1 \%$ agarose $/ 0.5 \times \mathrm{TBE} / 0.5 \mathrm{mg} / \mathrm{ml}$ ethidium bromine. Electrophoresis at $100 \mathrm{~V}$ for $30 \mathrm{~min}$ and visualized under UV light.

\section{Fluorescence in situ hybridization for TCL1 gene rearrangement}

Fluorescence in situ hybridization analysis was performed with a TCL1 probe set to detect rearrangements of the TCL1 gene cluster at the $14 \mathrm{q} 32.1$ locus that is commonly associated with T-cell prolymphocytic leukemia.

\section{Detection of anti-human T-cell leukemia virus type $1 / 2$ antibodies in serum}

Samples of patient serum were sent to a reference laboratory, where they were screened for antibodies against human Tcell leukemia virus type $1 / 2$, using in vitro chemiluminescent immunoassay (Abbott Prism). Positive cases were confirmed by a Line Immunoassay (INNO-LIA, Innogenetics).

\section{Results}

Two hundred twenty (220) patients with T-cell neoplasm and anti-human T-cell leukemia virus type 1/2 antibody detected in serum diagnosed and treated at our institution were identified. Of these, 9 patients $(4 \%)$ were correctly identified as adult T-cell leukemia/lymphoma because they had positive anti- human T-cell leukemia virus type $1 / 2$ serology results available at the time of initial diagnosis and/or had classic clinical presentations of acute or chronic type adult T-cell leukemia/lymphoma. Two hundred eleven patients (96\%) were initially classified as T-cell neoplasm other than adult T-cell leukemia/lymphoma and anti-human T-cell leukemia virus type $1 / 2$ antibody status was unknown at the time of diagnosis. Of these, $190(91 \%)$ were classified provisionally as peripheral T-cell lymphoma, not otherwise specified and anti-human T-cell leukemia virus type 1/2antibody testing was performed at initial diagnosis because of either significant leukemic involvement by highly atypical lymphoma cells, patient was known to be of high-risk demographic, unusual clinical presentation, or treating physician decision to not treat any T-cell neoplasm without knowledge of anti-human T-cell leukemia virus type 1/2 antibody status. The remaining 21 adult T-cell leukemia/ lymphoma cases (9\%) were misclassified as T-cell neoplasms and anti-human T-cell leukemia virus type 1/2 antibody testing was not initially performed. This set of cases is the focus of this work. Of these, $13(62 \%)$ mimicked mycosis fungoides/Sezary syndrome, 7 (33\%) mimicked ALK-negative anaplastic large-cell lymphoma, and $1(5 \%)$ mimicked T-cell prolymphocytic leukemia. Each of these is discussed in detail below. While composing this manuscript, we encountered 1 additional case of adult T-cell leukemia/lymphoma that we included in this review because of its striking morphologic resemblance to the lymphoepithelioid variant of peripheral T-cell lymphoma, not otherwise specified (Lennert lymphoma) with diffuse marrow involvement, features which are uncharacteristic of adult T-cell leukemia/lymphoma.

\section{Mycosis Fungoides/Sézary syndrome-like cutaneous adult T-cell leukemia/lymphoma}

Thirteen patients (6\%) from our adult T-cell leukemia/ lymphoma cohort presented with skin $+/$ - peripheral blood (PB) involvement and were misclassified as mycosis fungoides/Sézary syndrome or cutaneous T-cell lymphoma. This group represented $62 \%$ of our misclassified adult T-cell leukemia/lymphoma. Clinicopathologic features of these patients are summarized in Tables 1 and 2.

Patients included 10 females and 3 males (male:female ratio 0.3 ) with an average age of 61years (range: 35-80 years). All patients were of Afro-Caribbean or Brazilian origin, including 6 Haitians (46\%), 5 Jamaicans (38\%), 1 Dominican (8\%) and 1 Brazilian (8\%). One patient was human immunodeficiency virus positive. The most common presenting symptoms were rash (54\%), which was 


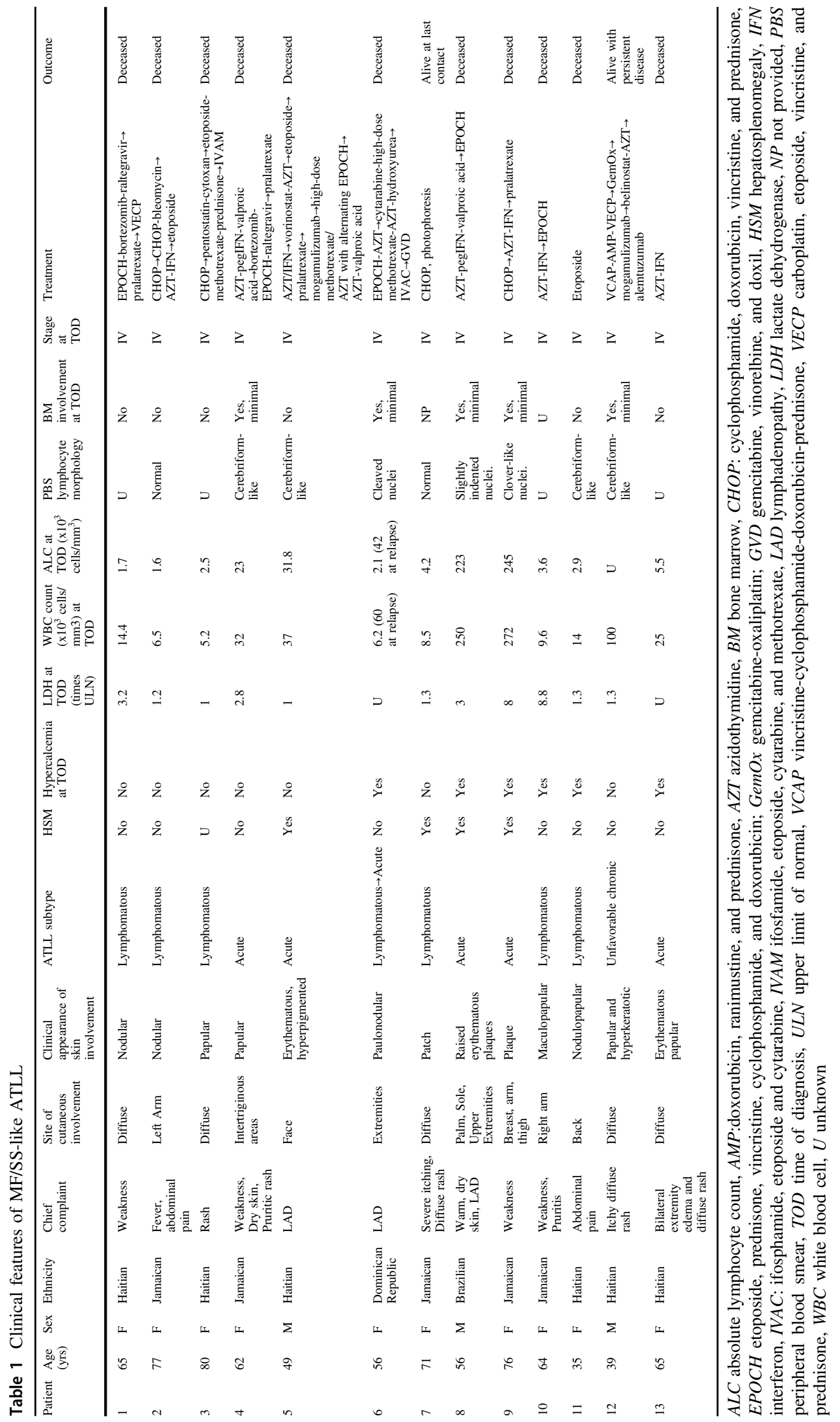




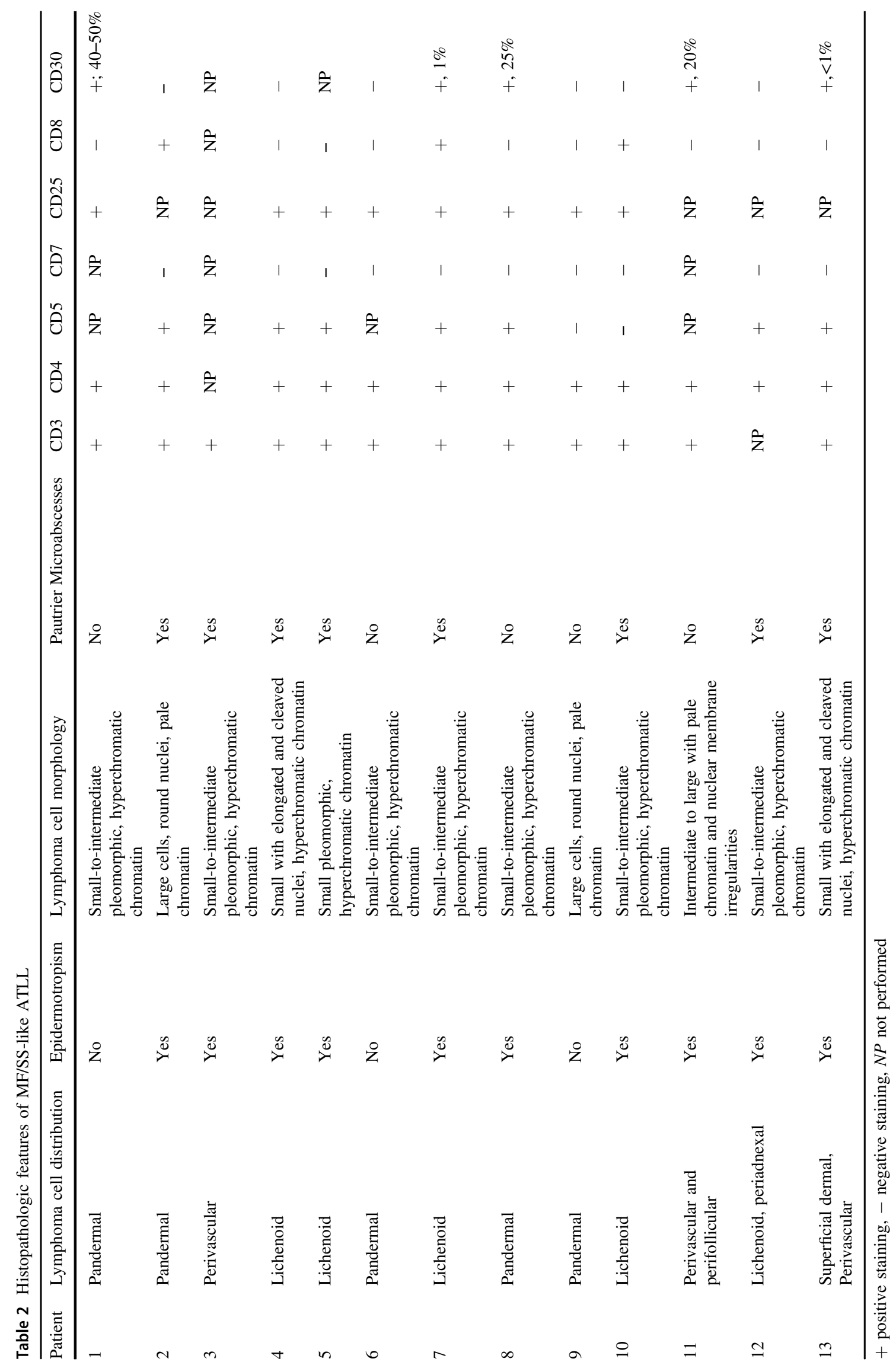


frequently pruritic (57\%), and weakness (31\%). Infrequent initial symptoms included fever, abdominal pain and lymphadenopathy. All patients had rash on physical examination. Sites of cutaneous involvement were restricted to sununexposed skin in one patient $(8 \%)$ but more commonly included sun-exposed and sun-unexposed skin or diffuse rash (92\%). Cutaneous lesions were most commonly nodulopapular (69\%), and less commonly hyperpigmented patches or erythematous plaques $(31 \%)$. Three patients (23\%) were found to have lymphadenopathy on initial physical examination and 4 of 12 patients with this information available had hepatosplenomegaly (33\%). Serum calcium was elevated in 6 patients $(46 \%)$ and lactate dehydrogenase was at least mildly elevated in $9(69 \%)$ at initial diagnosis. While most $(69 \%)$ of these patients had leukocytosis at the time of initial diagnosis with an average peripheral blood white blood cell count of 60,000 cells/ $\mathrm{mm}^{3}$, the range of white blood cell count at presentation varied greatly from 5000 cells $/ \mathrm{mm}^{3}$ to 272,000 cells $/ \mathrm{mm}^{3}$. The majority of patients had absolute lymphocytosis (77\%). Peripheral blood smears from initial diagnosis were not available for re-review as these slides are not archived. Reports of peripheral smear review from the time of initial diagnosis were available electronically, however, in 9 patients of which two (22\%) had no morphologic abnormalities and 7 (78\%) showed abnormal circulating lymphocytes. Morphologically abnormal circulating lymphocytes were described as having nuclei, which were "cerebriformlike" in four of these, mild-to-moderately indented or cleaved in two, and "clover-like" in one. The presence of atypical lymphocytes with cerebriform-like and mildto-moderately indented or cleaved nuclei were thought to be consistent with those of Sézary syndrome. The one case with abnormal lymphocytosis with "clover-like" nuclei should have prompted human T-cell leukemia virus type 1 status determination, but did not. Peripheral blood flow cytometry was performed in 4 patients and showed leukemic involvement by T-cell neoplasm, CD4 positive and T-cell receptor alpha beta type, three cases showing loss of CD7 expression and one with preserved CD7 expression. CD25 was expressed in at least a subset of lymphoma cells in 3 of 4 cases by flow cytometry. CD26 was not tested by flow cytometry in these cases.

Biopsy of cutaneous lesions identified involvement by T-cell lymphoma with lymphoma cells most often distributed in a lichenoid or superficial dermal pattern ( 6 cases, $46 \%$ ), the rest showed pandermal (5 cases, $38 \%$ ) or exclusively perivascular/perifollicular (2 cases, $15 \%$ ) distribution. Epidermotropism was present to varying degrees in 10 cases $(77 \%)$ and Pautrier microabscesses were present in 8 $(62 \%)$. The morphology of the lymphoma cells varied substantially among cases. Most biopsies showed lymphoma cells that were heterogeneous in size ranging from small-to-intermediate or large with irregular nuclear contours and hyperchromatic chromatin (8 cases, $62 \%)$; Three cases were composed of small pleomorphic or indented lymphoma cells (23\%), and two cases were composed predominantly of large lymphoma cells with round nuclear contours and open and vesicular nuclear chromatin (15\%). None of these cases had large and pleomorphic (hallmark) cells and none had Reed-Stenberg/Hodgkin-like cells.

Preserved expression of CD3 was seen in all cases in which it was performed and lymphoma cells were either CD4 positive or expressed both CD4 and CD8. CD7 expression was at least partially lost in each case in which it was tested and CD5 expression was lost in 2 tested cases (2/ 9; 25\%). CD25 was at least dim positive in all tested cases $(8 / 8,100 \%)$ but importantly was tested retrospectively at the time of lymphoma reclassification in all cases, in which it was performed. $\mathrm{CD} 30$ was positive to varying degrees in 5 of 11 tested cases $(45 \%)$. Extent of CD30 expression varied widely, ranging from rare positivity to up to $50 \%$ of lymphoma cells. The two cases composed predominantly of large cells were CD30 negative and none of the adult T-cell leukemia/lymphoma involving the skin mimicked Hodgkin lymphoma or CD30-positive lymphoproliferative disorder (lymphomatoid papulosis or primary cutaneous anaplastic large-cell lymphoma).

During the course of each patient's disease, progressive leukemic involvement and/or lymphadenopathy with increasing B symptoms became apparent and prompted anti-human T-cell leukemia virus type $1 / 2$ serology testing. Adult T-cell leukemia/lymphoma was of lymphomatous type by clinical criteria in 7 patients $(54 \%)$, acute type in 5 $(38 \%)$ and unfavorable chronic in $1(8 \%)$. Patients were treated with a variety of chemotherapeutic protocols (see Table 1). Eleven of thirteen patients have died of disease or disease related infection $(85 \%)$.

An example of mycosis fungoides-like adult T-cell leukemia/lymphoma is shown in Fig. 1 (patient 7, Tables 1 and 2). This patient was a 71-year-old Jamaican female who initially presented with severe itching and a diffuse cutaneous rash without peripheral blood lymphocytosis. Biopsy of skin rash showed involvement by lymphoma (Fig. 1). An interpretation of mycosis fungoides was made. Subsequently, she was found to have diffuse lymphadenopathy prompting human T-cell leukemia virus type 1/2 serology testing which was positive, thus the interpretation of the case was revised to cutaneous involvement by adult T-cell leukemia/lymphoma.

\section{ALK-negative anaplastic large-cell lymphoma-like adult T-cell leukemia/lymphoma}

Seven cases of adult T-cell leukemia/lymphoma were initially misclassified as ALK-negative anaplastic large-cell 
Fig. 1 Mycosis fungoides-like adult T-cell leukemia/ lymphoma. Hematoxylin and Eosin-stained slides demonstrate hyperkeratosis and cutaneous involvement by lymphoma within the superficial and deep dermis (A). Lymphoma cells are small in size, are cytologically atypical and have a lichenoid distribution along the dermalepidermal junction with epidermotropism (B) and Pautrier microabscess formation (C). CD4 immunohistochemistry confirms that the atypical lymphoid cells are of CD4-positive T-cell type (D). Image $A \times 200$ magnification, images $\mathbf{B}-\mathbf{D} \times 500$

magnification

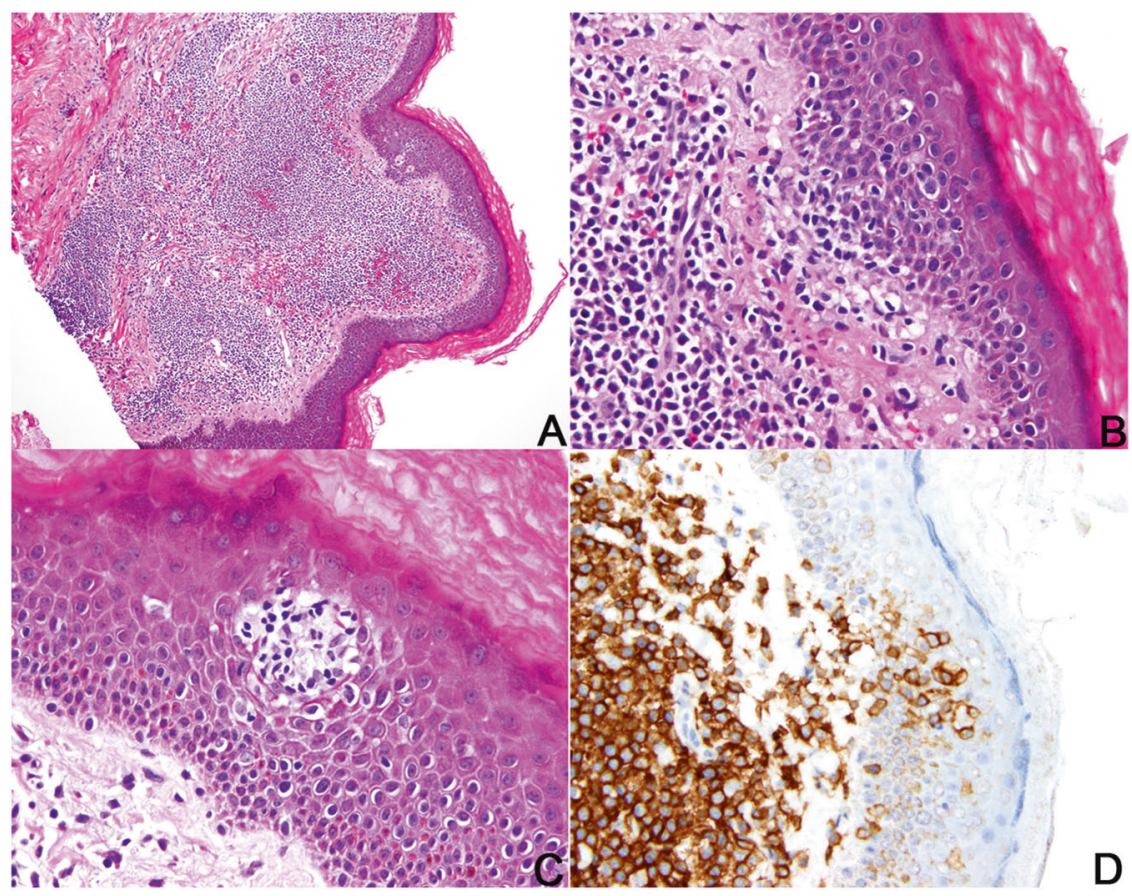

lymphoma, comprising $33 \%$ of our misclassified cases and $3 \%$ of our adult T-cell leukemia/lymphoma cohort. Clinicopathologic features of these cases are summarized in Tables 3 and 4 . These patients included 4 females and 3 males (male:female ratio 0.75 ) with an average age of 56 years (range 44-83 years). Four of these patients were of Haitian descent or Haitian residents (57\%), remaining patients were Panamanian, Jamaican and Venezuelan. One patient was human immunodeficiency virus positive. Presenting symptoms were most frequently mass-related pain (71\%). Fever, night sweats, shortness of breath and confusion were infrequent chief complaints. Presentation in all was lymphomatous in nature and peripheral blood lymphocytosis was absent. Serum calcium was normal in 5 of 7 patients, while serum lactate dehydrogenase was elevated in 4 of 6 patients (67\%) with this information available. Only one patient had hepatosplenomegaly.

Lymph nodes showed involvement by lymphoma composed of intermediate-to large-sized lymphoma cells present in diffuse distributions with varying degrees of cohesion and nodal sinusoidal involvement. All cases had pleomorphic lymphoma cells with anaplastic morphology and hallmark-like cells present. At the time of diagnosis, in all the cases, the tumor cells expressed CD30. Although most showed strong expression of CD30, one case was diffusely but weakly positive for CD30, mimicking small cell variant of anaplastic large-cell lymphoma which expresses diffuse but dim CD30 in the small cell component. ALK-1 protein expression was negative in all cases. CD25 was positive in 5 of the $6(83 \%)$ cases in which it was tested (retrospectively tested in all cases). One case (patient 1 ) showed few large B-cells positive for Epstein-Barr virus encoded RNA (EBER), the rest of the cases were negative. In order to confirm that this case (patient 1) was indeed adult T-cell leukemia/lymphoma, we performed polymerase chain reaction assays using human $\mathrm{T}$-cell leukemia virus type 1-specific primers for $E N V, G A G, P O L$ and $T A X$ genes in DNA extracted from the tumor sample, which was positive (results are shown in Fig. 2). TP63 and DUSP22 rearrangements were tested by fluorescence in situ hybridization in two of the cases, both were negative. During their disease course, all progressed to have leukemic phase or had subsequent biopsies at different anatomic sites in which lymphoma cells express CD30 in a subset of the tumor cells, prompting anti- human T-cell leukemia virus type $1 / 2$ antibody testing. Four of 5 patients treated with doxorubicin-based combination chemotherapy had initial responses $(80 \%, 1$ complete, 3 partial), however all later had relapsed or refractory disease. Four of these five patients have gone to hospice and are confirmed to be deceased. One patient is alive with active disease. One elderly patient (\#1) was treated with palliative radiation only, and then went to hospice. One patient (\#3) refused treatment and went to hospice.

An example of one case of anaplastic large-cell lymphoma-like adult T-cell leukemia/lymphoma with biopsies from separate time points is shown in Figs. 3 and 4. This patient was a 78-year-old Haitian female who initially presented with abdominal pain, anorexia and weight loss (patient 7, Tables 3 and 4). Imaging showed multiple enhancing lesions in the liver, perihilar and pleural masses. Biopsy of the liver mass demonstrated extensive 


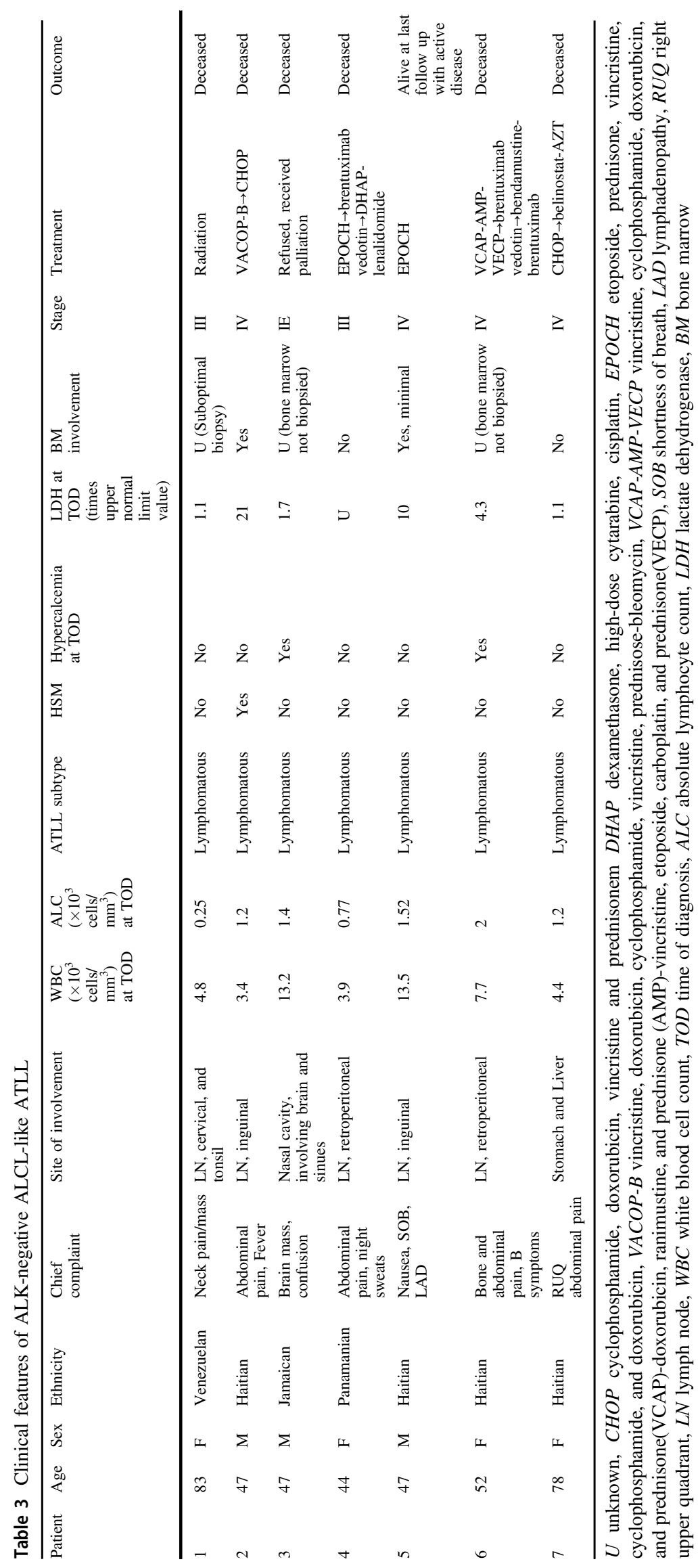




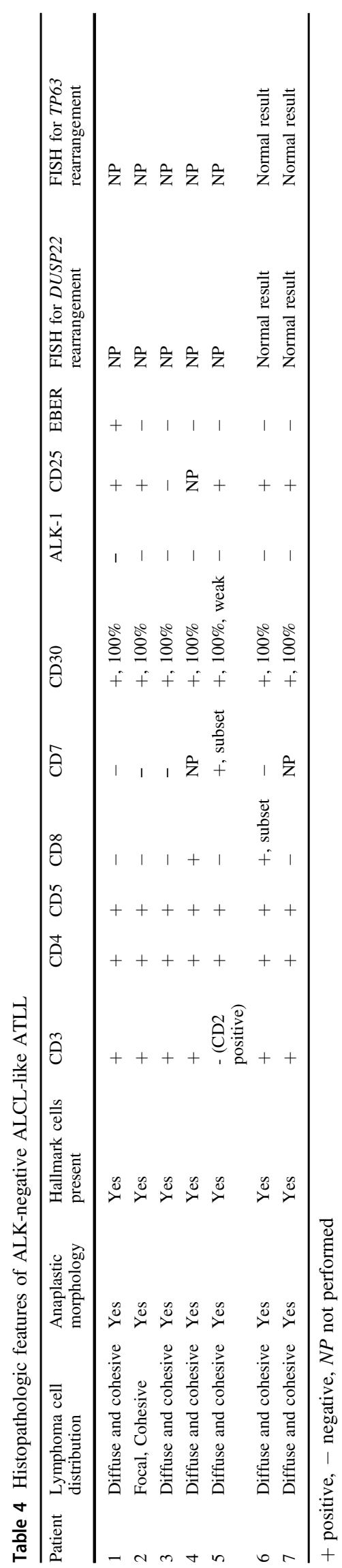

involvement by lymphoma (Fig. 3). A diagnosis of ALKnegative anaplastic large-cell lymphoma was made. The patient was started on CHOP chemotherapy.

A gastric endoscopy performed 6 months after initial diagnosis showed a $1.5-\mathrm{cm}$ greater curvature gastric ulcer, biopsy of which showed persistent large T-cell lymphoma, now largely CD30 negative (Fig. 4). Based on the focal CD30 expression seen in the gastric biopsy, which was unexpected and different than this patient's initial CD30positive lymphoma, the patient had serology testing for human T-cell leukemia virus type $1 / 2$ antibodies, which was positive. The patient's lymphoma was then reclassified as adult T-cell leukemia/lymphoma. CD25 immunohistochemistry stain was retrospectively performed in both patient biopsies (liver and gastric) and was diffusely and strongly positive (Figs. 3 and 4).

\section{T-cell prolymphocytic leukemia-like adult T-cell leukemia/lymphoma}

One case of adult T-cell leukemia/lymphoma in our series was initially thought to represent $\mathrm{T}$-cell prolymphocytic leukemia. This patient was a 70-year-old Haitian man who presented with marked lymphocytosis (white blood cell count 513,200 cells $/ \mathrm{mm}^{3}$ ), anemia, thrombocytopenia and elevated serum lactate dehydrogenase. Upon questioning, he reported generalized weakness, fatigue and upper body pain. Physical examination did not reveal skin lesions or hepatosplenomegaly. Peripheral smear review confirmed the presence of a lymphoproliferative process (Fig. 5a). Flow cytometry confirmed a CD4-positive T-cell neoplasm, T-cell receptor alpha/beta type, negative for CD25.

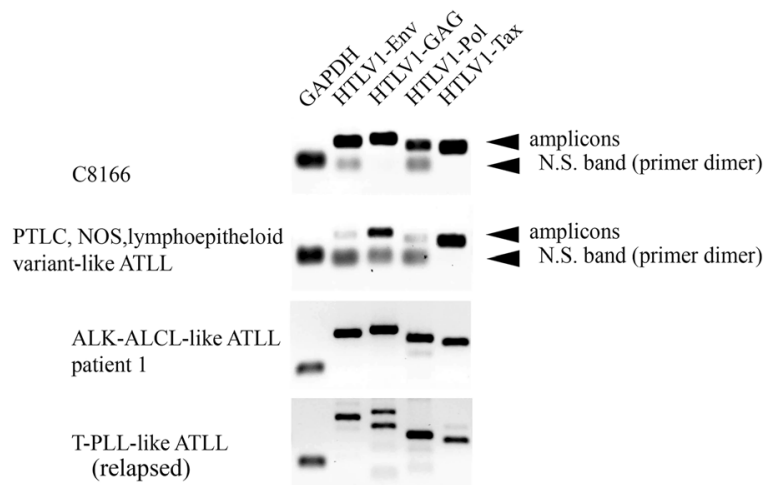

Fig. 2 Gel picture shows Touchdown polymerase chain reaction results using human T-cell leukemia virus type 1 specific primers for $E N V, G A G, P O L$, and TAX genes and DNA extracted from the indicated tumor specimens/patients. The human T-cell leukemia virus type 1 transformed cell line C8166 was included as human T-cell leukemia virus type 1 positive control (top panel). ALK-negative ALCL-like ATLL is shown in the third panel. PTCL, NOS, lymphoepitheloid variant-like ATLL and T-PLL-like ATLL are shown in panels 2 and 4 and are discussed later 
Fig. 3 ALK-negative anaplastic large-cell lymphoma-like adult T-cell leukemia/lymphoma, CD30 positive, liver biopsy. Hematoxylin and Eosin-stained histologic sections of a core needle biopsy of a liver mass demonstrate diffuse involvement by lymphoma. Lymphoma cells are large in size with significant pleomorphism and anaplastic morphologic features. Hallmark cells are present $(\mathbf{A})$. By immunohistochemistry, lymphoma cells are positive for CD3 (B), and diffusely strongly positive for $\mathrm{CD} 30(\mathbf{C})$.

Performed in retrospect, lymphoma cells are also positive for CD25 (D). Images A-D $\times 500$ magnification
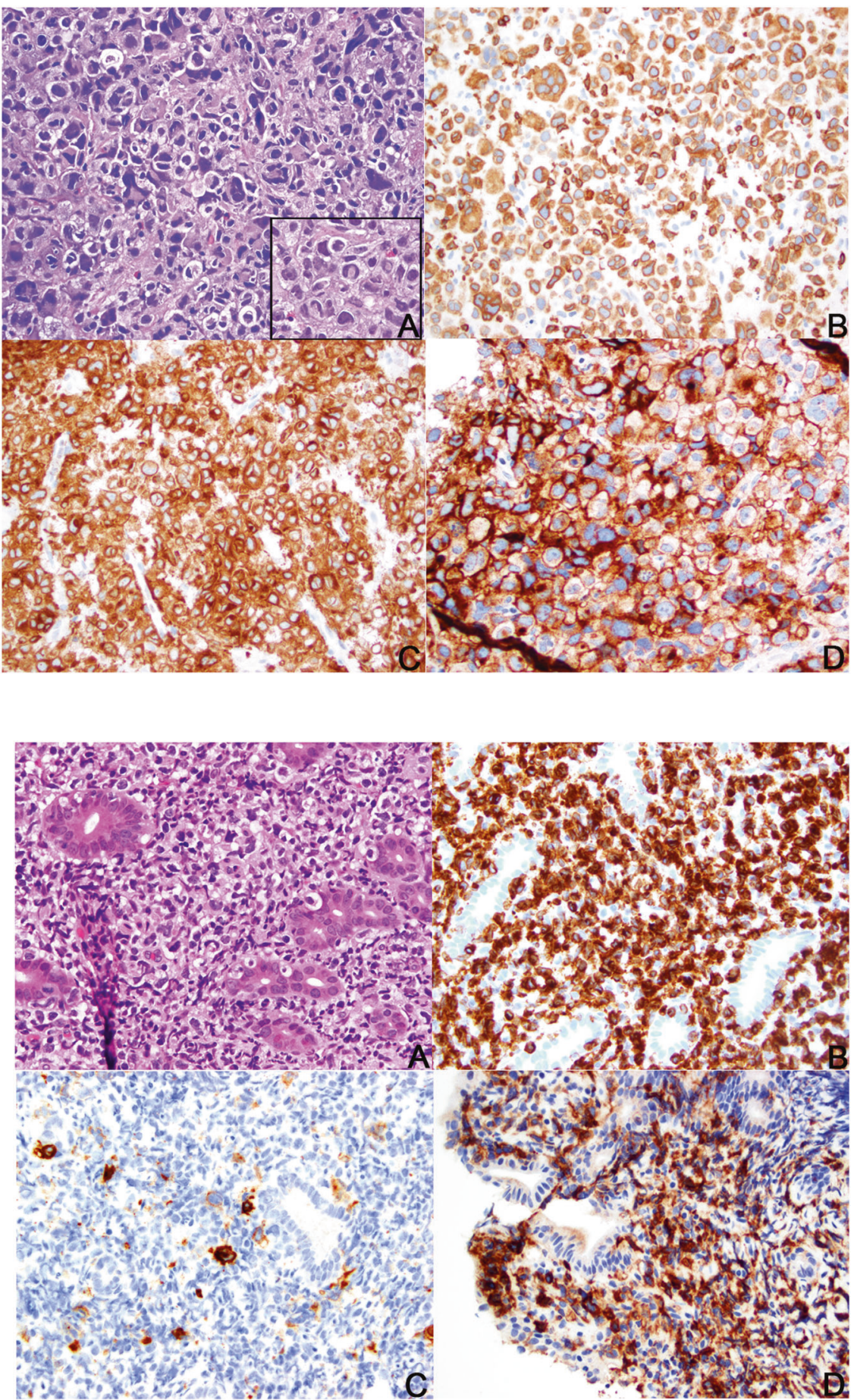

Fig. 4 Persistent ALK-negative anaplastic large-cell lymphomalike adult T-cell leukemia/ lymphoma, with focal CD30 expression, gastric biopsy, 6 months after initial diagnosis, same patient as Fig. 3 .

Hematoxylin and Eosin-stained histologic section of gastric mucosa demonstrates diffuse involvement by lymphoma composed of intermediate-sized cytologically atypical lymphoid cells (A). Immunohistochemical studies showed that lymphoma cells are positive for CD3 (B) but only rarely for CD30 (C). $\mathrm{CD} 25$ is positive in a subset of lymphoma cells (D). Images A-D $\times 500$ magnification
Bone marrow biopsy showed extensive marrow involvement by a T-cell neoplasm composed of small-tointermediate-sized lymphoid cells, which comprised $\sim 80 \%$ of the marrow cellularity (Fig. 5b, c). Lymphoma cells were positive for $\mathrm{CD} 3$ and $\mathrm{CD} 4$ and negative for CD25, TIA-1 and CD30. EBER testing by in situ hybridization was negative.

Despite the fact that lymphoma cells had an atypical immunophenotype (positive for CD7, negative for CD25), 


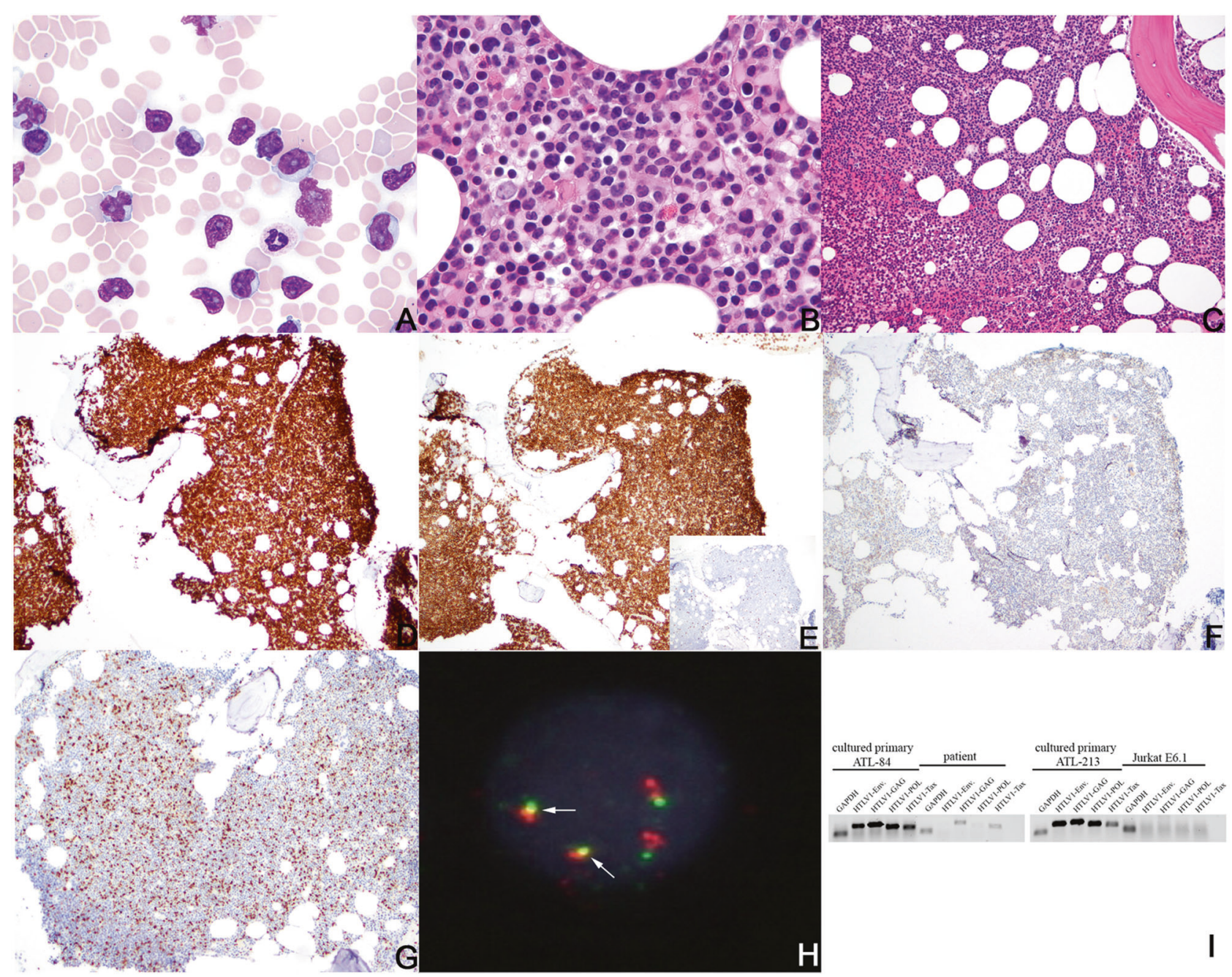

Fig. 5 T-cell prolymphocytic lymphoma-like adult T-cell leukemia/ lymphoma, TCL-1 gene rearrangement positive. Peripheral blood smear demonstrates leukemic involvement by intermediate-to-largesized lymphoma cells with irregular nuclear contours, conspicuous nucleoli and abundant cytoplasm (A, Wright Giemsa stain, $\times 1000$ magnification). Bone marrow core biopsy shows diffuse interstitial involvement by lymphoma composed of small-to-intermediate-sized lymphoid cells with cytologic atypia in the form of nuclear membrane irregularities (B, C; Hematoxalin \& Eosin stain, $\times 1000$ and $\times 200$ magnification, respectively). Immunohistochemistry assays confirm that lymphoma cells are CD3 positive (D) T-cells of CD4-positive type
(E), negative for CD8 (E, inset) and CD25 (F) but positive for TCL-1 protein expression $(\mathbf{G})$. Fluorescence in situ hybridization for TCL1 rearrangement was positive (H, arrow). Gel picture shows polymerase chain reaction results using human T-cell leukemia virus type 1specific primers for $T A X, G A G$ and $P O L$ genes and DNA extracted from peripheral blood mononuclear cells from our patient (white blood cell count was 1300 cells $/ \mathrm{mm}^{3}$ after leukapheresis and alemtuzumab therapy), ATL-84 and ATL-213 primary cell lines (used as human Tcell leukemia virus type 1-positive control), and Jurkat cell line (used as human T-cell leukemia virus type 1 negative control) (I). Images D-F- 200 times magnification, $\mathbf{G} \times 400$ times magnification the bone marrow pattern of involvement was diffuse and TCL-1 protein expression and TCL- 1 rearrangement were present, all unusual features for typical adult T-cell leukemia/lymphoma, still serology testing for human T-cell leukemia virus type $1 / 2$ antibodies was requested by us because the patient was of Haitian descent and did not have hepatosplenomegaly. Serology testing was positive, supporting the diagnosis of adult T-cell leukemia/lymphoma with $T C L$ 1 gene rearrangement. To further confirm the diagnosis of adult T-cell leukemia/lymphoma, we performed polymerase chain reaction using human T-cell leukemia virus type 1specific primers on DNA isolated from fresh peripheral blood mononuclear cells at two time points: initially polymerase chain reaction was performed after multiple rounds of leukophoresis followed by alemtuzumab treatment (white blood cell count was 1,300 cells $/ \mathrm{mm}^{3}$ with low lymphocyte count at the time, Fig. 5); Polymerase chain reaction was repeated at subsequent disease relapse when the patient's white blood cell count was markedly elevated (Fig. 2). While the patient had an initial excellent hematologic 


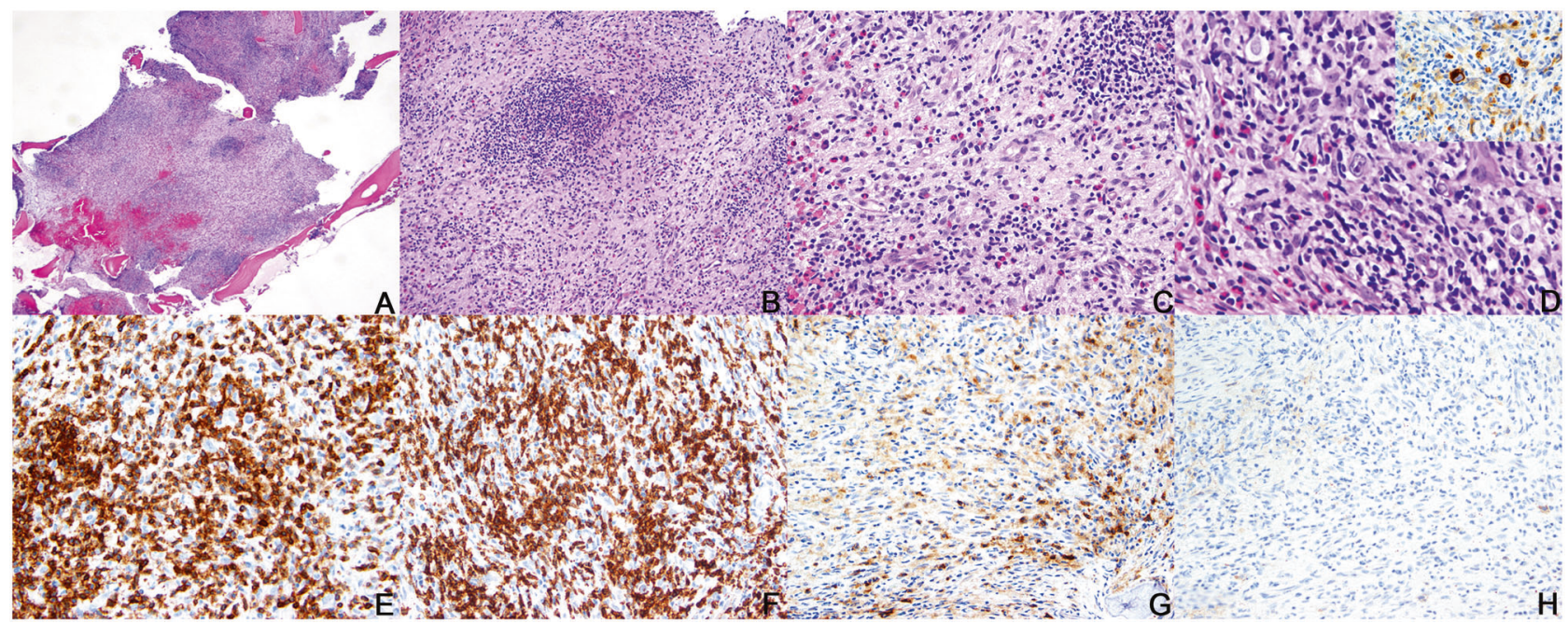

Fig. 6 Peripheral T-cell lymphoma, not otherwise specified, lymphoepithelioid variant-like adult T-cell leukemia/lymphoma. Bone marrow core biopsy demonstrates extensive marrow involvement by a hematolymphoid neoplasm, which replaces hematopoietic marrow (A). The infiltrate is polymorphic in appearance and composed of small-to-intermediate-sized cytologically atypical lymphoid cells, in association with abundant histiocytes, scattered and loosely clustered eosinophils, plasma cells and fibroblasts (B, C). Scattered large, Hodgkin-like cells are present (D) and express CD30 by immunohistochemistry (D, inset). The majority of lymphoma cells express CD3 $(\mathbf{E})$ and CD8 $(\mathbf{F})$ and lack expression of CD4 $(\mathbf{G})$ and CD25 (H). Hematoxylin and Eosin-stained images taken at $400(\mathbf{A}), \times 200(\mathbf{B}, \mathbf{C})$ and $\times 500$ (D) magnification. Immunohistochemistry images taken at $\times 200$ imagnification $(\mathbf{E}-\mathbf{H})$ response to alemtuzumab, zidovudine (AZT) and interferon, he has since shown progressive disease. Interestingly, the $E N V$ gene revealed 2 different size fragments (confirmed on 2 separate repeat PCR experiments), with a smaller size band, which could be due to the presence of an additional defective provirus copy in the tumor, which in our experience can occur in adult T-cell leukemia/lymphoma.

\section{Peripheral T-cell lymphoma, not otherwise specified, lymphoepithelioid variant-like adult T-cell leukemia/lymphoma (ATLL)}

This patient was a 70-year-old male who arrived at our medical center from Ecuador with a history of positive serum anti-human T-cell leukemia virus type 1/2 antibody and 9 months of fever and night sweats, treated without response with empiric antibiotics. He had splenomegaly and elevated lactate dehydrogenase but serum calcium and peripheral blood counts were normal. Imaging studies showed mediastinal, subcarinal, hilar, and axillary lymphadenopathy. CT-PET scan showed diffuse metabolic enhancement of bone marrow throughout the skeleton with standardized uptake values (SUV) up to 3.7 .

Bone marrow biopsy demonstrated extensive involvement by lymphoma characterized by a polymorphic population of cytologically atypical small-to-medium-sized lymphoid cells admixed with abundant histiocytes, scattered eosinophils, mast cells, plasma cells, and fibroblasts (Fig. 6). Scattered Hodgkin-like large lymphoid cells with prominent nucleoli were also seen. The small-tomedium-sized lymphoma cells were positive for CD3 and CD8 with preserved expression of CD5 and CD7 and were negative for CD4 and CD25. The scattered Hodgkin-like large cells additionally coexpressed strong CD30. Rare EBER-positive reactive B-cells were present. Because this patient's human T-cell leukemia virus type 1 status was known at the time of presentation, this case was classified as adult T-cell leukemia/lymphoma, lymphoepithelioid variant. However, had this information not been available to us, it is likely that this case would have been classified as peripheral T-cell lymphoma, not otherwise specified (PTCL, NOS), lymphoepithelioid (Lennert) variant. Due to the unusual histopathologic features in this case, polymerase chain reaction for detection of human T-cell leukemia virus type 1-specific genes was performed in tumor tissue macrodissected from the formalin-fixed, paraffinembedded tissue sections and confirmed the presence of human T-cell leukemia virus type 1 derived $E N V, G A G$, $P O L$ and $T A X$ (Fig. 2).

The patient was then treated with VCAP (vincristine, cyclophosphamide, doxorubicin, prednisone) then DP (doxorubicin/prednisone) with the intent to simulate regimen LSG-15 (Japanese regimen VCAP-AMP-VECP), but the regimen proved to be too toxic for him. He then received 2 cycles of carboplatin/etoposide/prednisone with dose reductions followed by 2 monthly cycles of alemtuzumab, but CT-PET scan showed interval development of multiple hypermetabolic lymph nodes in the head and neck, chest, abdomen, pelvis and groins with possible new 
involvement of the liver, and widespread hypermetabolic bone lesions.

\section{Discussion}

In our cohort of 220 patients, $199(91 \%)$ were appropriately diagnosed with adult T-cell leukemia/lymphoma or provisionally as peripheral T-cell lymphoma with human T-cell leukemia virus type 1/2 serology testing ordered. Most of these patients were identifiable because they had leukemic phase adult T-cell leukemia/lymphoma with lymphoma cells in peripheral blood with typical adult T-cell leukemia/ lymphoma morphology, often in association with hepatosplenomegaly, diffuse lymphadenopathy, elevated lactate dehydrogenase and hypercalcemia. A subset of these patients was identified based on the treating physician's decision to determine human T-cell leukemia virus type 1 status in all patients with T-cell neoplasms. This selection bias is discussed further below. Conversely, 21 adult T-cell leukemia/lymphoma cases, $9 \%$ of our series, were T-cell neoplasms that presented either without leukemic involvement (lymphomatous adult T-cell leukemia/lymphoma) or had leukemic and cutaneous involvement that mimicked mycosis fungoides/Sézary syndrome or T-cell prolymphocytic leukemia and did not initially raise suspicion for adult T-cell leukemia/lymphoma.

Adult T-cell leukemia/lymphoma misclassified as mycosis fungoides/Sézary syndrome represented the most frequent misclassification in our cohort, comprising $62 \%$ of misclassified cases. Concordant with other reports in the literature, these cases support that initially isolated cutaneous (cutaneous adult T-cell leukemia/lymphoma) or cutaneous and leukemic involvement by smoldering or chronic adult T-cell leukemia/lymphoma can be misdiagnosed as mycosis fungoides or mycosis fungoides/ Sézary syndrome in the absence of human T-cell leukemia virus type 1 identification. This misidentification is problematic given the inevitable progression and poor prognosis of adult T-cell leukemia/lymphoma.

Cutaneous involvement as a manifestation of systemic adult T-cell leukemia/lymphoma is frequently observed in all clinical adult T-cell leukemia/lymphoma subtypes, the incidence of which varies from 43 to $72 \%[9,14]$. The majority of cutaneous lesions of adult T-cell leukemia/ lymphoma are composed of either small pleomorphic lymphoma cells with markedly irregular nuclei or large pleomorphic lymphoma cells, both scenarios seen most commonly when acute type systemic adult T-cell leukemia/ lymphoma secondarily involves skin. Degree of involvement and cytologic atypia can be much more subtle, however, when chronic or smoldering type adult T-cell leukemia/lymphomainvolves skin or when adult T-cell leukemia/lymphoma is primarily cutaneous. In such cases, the histopathologic and clinical features may be compatible with those of much more common mycosis fungoides or Sézary syndrome [14-17].

Regarding the differential diagnosis of adult T-cell leukemia/lymphoma and mycosis fungoides or Sézary syndrome in general, cutaneous involvement by adult T-cell leukemia/lymphoma is usually composed of a relatively more monotonous population of lymphoma cells and lacks reactive histiocytes, lymphocytes and granulocytes compared to mycosis fungoides. However, these features can be nonspecific, poorly sensitive, and therefore unreliable or at least difficult to apply in individual cases. The morphologic subtleties that differentiate mycosis fungoides from cutaneous involvement by adult T-cell leukemia/lymphoma are most difficult to appreciate in smoldering/chronic adult T-cell leukemia/lymphoma and cutaneous-restricted adult T-cell leukemia/lymphoma, where the cytologic atypia of adult T-cell leukemia/lymphoma cells is more subtle and therefore more mycosis fungoides-like. These are also the patients who more commonly lack hepatosplenomegaly, hypercalcemia and elevated lactate dehydrogenase, thus they can also be misclassified from a clinical perspective.

Primarily cutaneous and cutaneous/leukemic adult T-cell leukemia/lymphoma with mycosis fungoides or Sézary syndrome-like features have been previously reported [16, 18]. Primarily cutaneous mycosis fungoides-like adult T-cell leukemia/lymphoma typically presents with skin rashes and/or with dermal nodules (unusual in mycosis fungoides at presentation) and histologic features, including epidermitrophism and Pautrier microabscesses. In two separate studies, Takahashi and Dosaka each described a cutaneous type of smoldering adult T-cell leukemia/lymphoma, in which patients had predominantly or strictly cutaneous involvement by adult T-cell leukemia/lymphoma. In these patients, cutaneous T-cell neoplasms with monoclonal expansions of T-helper cells having integrated human T-cell leukemia virus type 1 were identified in skin biopsies. Peripheral blood was either negative for the presence of clonal T-cells or clonal T-cells were present at a rate of $<1 \%$, despite the fact that high titer antibody against human $\mathrm{T}$-cell leukemia virus type 1 was present. These previously reported examples highlight that adult T-cell leukemia/ lymphoma can be restricted to skin with minimal or no detectable systemic (peripheral blood) involvement and that when this occurs the lymphoma closely resembles more common cutaneous T-cell neoplasms such as mycosis fungoides. The disease course of this "smoldering cutaneous adult T-cell leukemia/lymphoma" was reported to be relatively indolent, at least initially $[15,16]$. Similarly, Johno et al. also described a type of cutaneous adult T-cell leukemia/lymphoma restricted to the skin with no involvement of internal organs, lymphadenopathy, lymphocytosis, or 
hypercalcemia. These lymphomas could not be classified into any of the Shimoyama clinical types and were therefore defined as the primary cutaneous tumoral type of adult T-cell leukemia/lymphoma [19].

If the differential diagnoses of mycosis fungoides or Sézary syndrome and adult T-cell leukemia/lymphoma are considered at the time of lymphoma diagnosis, immunophenotyping can be useful in distinguishing these entities given that adult T-cell leukemia/lymphoma more commonly coexpresses CD25, CCR4 and FoxP3 [6, 12, 20]. However, caveats include that other T-cell neoplasms aside from adult T-cell leukemia/lymphoma can express these markers, including a subset of mycosis fungoides and peripheral T-cell lymphoma, not otherwise specified [7, 8, 21]. Although initially considered specific for adult T-cell leukemia/lymphoma, expression of FoxP3 has now been reported in cutaneous T-cell lymphoma, including mycosis fungoides, peripheral T-cell lymphoma, not otherwise specified and anaplastic large-cell lymphoma [21]. Additionally, as in the cases presented here, adult T-cell leukemia/ lymphoma may not be initially considered because of the histologic and clinical overlap with the more common mycosis fungoides or Sézary syndrome, thus these distinguishing tests may not be performed. Based on our experience with these types of adult T-cell leukemia/lymphoma, we suggest that at least CD25 immunohistochemistry staining be performed in all newly diagnosed cases of cutaneous T-cell lymphoma as a screen for adult T-cell leukemia/lymphoma in patients of appropriate demographic. While not specific, the combination of CD25 and FoxP3 expression in this context raises the possibility of adult T-cell leukemia/lymphoma and could therefore prompt appropriate serology or viral integration studies.

In this review, we also report 7 cases of adult T-cell leukemia/lymphoma that were initially classified as ALKnegative anaplastic large-cell lymphoma, representing 3\% of our adult T-cell leukemia/lymphoma cohort and 33\% of our misclassified cases. Anaplastic large-cell lymphoma, in contrast to adult T-cell leukemia/lymphoma, has predictable and reproducible histopathologic features. Unfortunately, a subset of adult T-cell leukemia/lymphoma can mimic these. Anaplastic large-cell lymphoma is usually composed of cohesive medium-to-large-sized pleomorphic lymphoma cells with frequent sinusoidal involvement. Strong and uniform expression of CD30 is a requirement. The combination of these features is the hallmark of anaplastic largecell lymphoma and is used to make this diagnosis. We report a series of adult T-cell leukemia/lymphoma that fit these diagnostic criteria and which presented with lymphomatous involvement in the absence of leukemic phase. The most common reasons for anti- human T-cell leukemia virus type $1 / 2$ serology testing in this group were patient demographic and subsequent biopsy that was positive for persistent lymphoma, but which did not demonstrate diffuse CD30 expression. The common development in these cases of subsequent lymphoma site involvement in which lymphoma cells were CD30 negative and/or development of florid leukemic involvement (transition to acute phase adult T-cell leukemia/lymphoma) supports that these lymphomas were not anaplastic large-cell lymphoma. This is an important point given that anti- human T-cell leukemia virus type $1 / 2$ serology testing, which we used to support the final interpretation of adult T-cell leukemia/lymphoma in these cases, is not necessarily diagnostic of adult T-cell leukemia/lymphoma, particularly when performed in patients from human T-cell leukemia virus type 1 endemic areas.

From the clinical standpoint, ALK-negative anaplastic large-cell lymphoma, similar to adult T-cell leukemia/lymphoma, can have leukemic phase, diffuse systemic involvement including bone, progressive disease and poor prognosis. Given that the clinical progression of these tumors is similar, CD30-positive lymphomatous adult T-cell leukemia/lymphoma, misclassified as ALK- anaplastic large-cell lymphoma, would not typically raise suspicion of lymphoma misclassification. Regarding immunophenotype, although adult T-cell leukemia/lymphoma, including lymphomatous type typically expresses $\mathrm{CD} 25$ and FoxP3, and do not express cytotoxic markers, neither the presence of $\mathrm{CD} 25$ and FoxP3 expression nor the lack of cytotoxic marker expression excludes ALK-negative anaplastic large-cell lymphoma [22, 23]. In fact, anaplastic large-cell lymphoma commonly expresses CD25, have been reported to express FoxP3, and can lack cytotoxic markers $[22,24]$. In such cases, the only reproducible mechanism for lymphoma classification may be identification of clonally integrated human T-cell leukemia virus type 1virus within lymphoma cells or the assumption of clonal integration based on positive serology testing for anti- human T-cell leukemia virus type $1 / 2$ antibody.

A subset of adult T-cell leukemia/lymphoma is known to express CD30, the extent of which varies widely from 0 to $100 \%$ [13, 25-27]. In cultured cells, human T-cell leukemia virus type 1 viral-encoded protein TAX induces CD21/ Epstein-Barr Virus Receptor expression on $\mathrm{T}$ cells and this in turn induces CD30 expression in lymphoma cells in adult T-cell leukemia/lymphoma [28]. Similar to our findings in this report, few other previous studies have also shown that rare lymphomas that meet diagnostic criteria for anaplastic large-cell lymphoma have been associated with human T-cell leukemia virus type 1 infection, as demonstrated in blood serology testing and identification of integrated human T-cell leukemia virus type 1within lymphoma cells [25-27]. Takeshita et al. identified that $18 \%$ of adult T-cell leukemia/lymphoma cases from human T-cell leukemia virus type 1 endemic areas showed CD30 expression by 
lymphoma cells [25, 26]. While extent of CD30 expression was not specified in this previous report, the histologic findings of the CD30-positive adult T-cell leukemia/lymphoma cases included pleomorphic medium and large-sized lymphoma cells similar to those seen in anaplastic large-cell lymphoma $[25,26]$. In this previously reported series, CD30-positive and CD30-negative adult T-cell leukemia/ lymphoma had otherwise similar phenotypic expression patterns and all showed complete integration of human T-cell leukemia virus type 1 proviral DNA [25, 26]. Interestingly, and similar to our cases herein reported, the CD30positive adult T-cell leukemia/lymphoma with pleomorphic or anaplastic morphologic features frequently showed an intrasinusoidal distribution of lymphoma cells with a loosely cohesive growth pattern in lymph node and extranodal sites, features, which create a striking overlap with anaplastic large-cell lymphoma. Further, these patients presented with lymphadenopathy and extranodal tumors mainly of the subcutis, bone, gastrointestinal tract and soft tissue. Leukemic, bone marrow and hepatosplenic involvement and hypercalcemia were rarely found.

Takeshita et al. analyzed cell adhesion molecules of anaplastic large-cell lymphoma-like-adult T-cell leukemia/ lymphoma and demonstrated that, similar to anaplastic large-cell lymphoma, the lymphoma cells are frequently positive for CD54 (ICAM1) and negative for LFAl $\alpha$. In contrast, CD30-negative adult T-cell leukemia/lymphoma was most commonly negative for ICAM1 and positive for LFAl $\alpha$. It is speculated that the positivity for CD54 (ICAM1) and negativity for LFAl $\alpha$ seen in the anaplastic large-cell lymphoma-like-adult T-cell leukemia/lymphoma might be related to local tumor formation and aleukemic presentations, similar to those of anaplastic large-cell lymphoma $[25,29]$. These types of lymphomatous presentations of diffusely CD30-positive adult T-cell leukemia/ lymphoma are easily misdiagnosed as ALK-negative anaplastic large-cell lymphoma, particularly when they occur in non-human T-cell leukemia virus type 1 endemic populations, such as the United States. Recognition of this adult Tcell leukemia/lymphoma variant presentation is important, given that lymphomatous presentations of adult T-cell leukemia/lymphoma are more common in the Western world and include those that are CD30 positive.

We report a single case of adult T-cell leukemia/lymphoma which closely mimicked $\mathrm{T}$-cell prolymphocytic leukemia, representing $0.5 \%$ of our series. In this case, TCL-1 protein expression and TCL- 1 gene rearrangement were present, serology testing for anti-human T-cell leukemia virus type $1 / 2$ antibodies was positive and polymerase chain reaction assays identified human T-cell leukemia virus type 1 derived proteins in isolated lymphoma cells, confirming the diagnosis of adult T-cell leukemia/lymphoma with TCL-1 gene rearrangement. To our knowledge, $T C L-1$ gene rearrangement is not previously reported in adult T-cell leukemia/lymphoma. Similar to mycosis fungoides-like and ALK-negative anaplastic largecell lymphoma-like adult T-cell leukemia/lymphoma, this case is easily misclassified as T-cell prolymphocytic leukemia in the absence of suspicion for adult T-cell leukemia/ lymphoma.

T-cell prolymphocytic leukemia is reportedly unique among T-cell lymphomas in its expression of TCL1 protein, which can be detected by immunohistochemistry, and for the presence of $T C L-1$ gene rearrangements [30]. The case we present, however, shows that rarely adult T-cell leukemia/lymphoma can also have TCL-1 protein expression and $T C L-1$ rearrangement. The aggressive nature and short overall survival of T-cell prolymphocytic leukemia (T-PLL) are similar to those of adult T-cell leukemia/lymphoma, thus it is possible that a subset of adult T-cell leukemia/lymphoma, which are classified as T-cell prolymphocytic leukemia, remains unrecognized.

Similarly, herein we report a case of systemic adult T-cell leukemia/lymphoma with extensive bone and marrow involvement in which histopathologic and clinical features are similar to those of the lymphoepithelioid variant of peripheral T-cell lymphoma not otherwise specified. We believe that this case is also easily misclassified in the absence of anti-human T-cell leukemia virus type 1/2 serology testing, which again must be performed based on patient demographic alone. Features unusual for adult T-cell leukemia/lymphoma in this case included extensive bone marrow involvement, presence of a polymorphic infiltrate and lymphoma cell immunophenotype (positive for CD8 with preserved expression of CD5 and CD7 and lack of CD4 and CD25). Similar to the T-cell prolymphocytic leukemia-like adult T-cell leukemia/lymphoma case described above, this example demonstrates that a subset of adult T-cell leukemia/lymphoma present with diffuse marrow involvement with or without leukemic phase, unexpected morphologic features, and unusual immunophenotype. These cases of adult T-cell leukemia/ lymphoma are particularly difficult to identify.

In summary, reliable distinction of a subset of adult T-cell leukemia/lymphoma from other T-cell neoplasms using clinical presentation, morphology and immunophenotype can be difficult if not impossible. In this report we describe a set of adult T-cell leukemia/lymphoma with unusual clinicopathologic features, which led to erroneous classifications. Despite the inherent difficulty, prompt recognition of adult T-cell leukemia/lymphoma has important prognostic and therapeutic implications.

One weakness of this study is that all cases of T-cell neoplasm in patients with anti- human T-cell leukemia virus type 1antibody were classified by us as adult T-cell leukemia/lymphoma. While it is likely that human T-cell 
leukemia virus type 1 seropositive patients who develop a T-cell neoplasm have adult T-cell leukemia/lymphoma, it is conceivable that patients infected with human T-cell leukemia virus type 1could develop a non-adult $\mathrm{T}$-cell leukemia/lymphoma $\mathrm{T}$-cell neoplasm. Indeed, as the incidence of human T-cell leukemia virus type 1 seropositivity within a population increases, the likelihood of non-adult T-cell leukemia/lymphoma T-cell neoplasms increases and in these circumstances identification of human T-cell leukemia virus type 1 integration within tumor cells may be required for lymphoma classification. This type of identification was performed in a subset of the cases presented here. In addition, the clinical progression and outcomes described in this data set are in keeping with those of adult T-cell leukemia/lymphoma, supporting these interpretations.

Additionally, the classification of some T-cell neoplasms in this series was impacted by happenstance. Specifically, a selection bias was introduced based on the treating physician to whom the patient was assigned given that some of our clinicians do not treat T-cell neoplasms without knowledge of human T-cell leukemia virus type 1 status, a decision which is based on their personal experience. Misclassified T-cell neoplasms treated by such clinicians in our system would have been reclassified prior to therapy and considered as appropriately classified for the purposes of this report. Given the data available to us from clinical and pathology records, we are not able to identify these cases within our series. It stands to reason, therefore, that additional cases of adult T-cell leukemia/ lymphoma which were not specifically recognizable from histopathologic grounds exist in our series within the category of correctly identified adult T-cell leukemia/ lymphoma.

On the basis of our findings, we suggest anti-human T-cell leukemia virus type $1 / 2$ serology testing be performed in all patients with T-cell neoplasms who are of a demographic that puts them at risk for history of human T-cell leukemia virus type 1 exposure. In the absence of high level of suspicion, which must often be based on patient demographic alone, a subset of adult T-cell leuke$\mathrm{mia} / \mathrm{lymphoma}$ is easily misclassified.

\section{Compliance with Ethical Standards}

Conflict of interest :The authors declare that they have no conflict of interest.

\section{References}

1. Uchiyama T, Yodoi J, Sagawa K, et al. Adult T-cell leukemia: clinical and hematologic features of 16 cases. Blood. 1977;50:481-92.
2. Gessain A, Cassar O. Epidemiological Aspects and World Distribution of HTLV-1 Infection. Front Microbiol. 2012;3:388.

3. Shimoyama M. Diagnostic criteria and classification of clinical subtypes of adult T-cell leukaemia-lymphoma. A report from the Lymphoma Study Group (1984-87). Br J Haematol. 1991;79:428-37.

4. Yoshino T, Jaffe ES. In: Jaffe ES, Arber DA, Campo E, et al., Adult T-cell leukemia / lymphoma. editors. Hematopathology. 2nd edn. Philadelphia, PA: Saunders/Elsevier; 2016. pp. 619-29.

5. Lyra-da-Silva JO, de Mello Gonzaga YB, de Melo, Espindola $\mathrm{O}$, et al. Adult T-cell leukemia/lymphoma: a case report of primary cutaneous tumoral type. Dermatol Pract Concept. 2012;2:3.

6. Janik JE, Morris JC, Pittaluga S, et al. Elevated serum-soluble interleukin-2 receptor levels in patients with anaplastic large cell lymphoma. Blood. 2004;104:3355-7.

7. Fujimura T, Okuyama R, Ito Y, et al. Profiles of Foxp3 + regulatory $\mathrm{T}$ cells in eczematous dermatitis, psoriasis vulgaris and mycosis fungoides. Br J Dermatol. 2008;158:1256-63.

8. Hallermann C, Schulze HJ, Neumann C, et al. The regulatory T-cell phenotype in progressive mycosis fungoides. G Ital Dermatol Venereol. 2008;143:15-9.

9. Bittencourt AL, Barbosa HS, Vieira MD, et al. Adult T-cell leukemia/lymphoma (ATL) presenting in the skin: clinical, histological and immunohistochemical features of 52 cases. Acta Oncol. 2009;48:598-604.

10. Yao J, Gottesman SR, Ayalew G, et al. Loss of Foxp3 is associated with CD30 expression in the anaplastic large cell subtype of adult T-cell leukemia/lymphoma (ATLL) in US/Caribbean patients: potential therapeutic implications for CD30 antibodymediated therapy. Am J Surg Pathol. 2013;37:1407-12.

11. Ishida $T$, Utsunomiya $A$, Iida $S$, et al. Clinical significance of CCR4 expression in adult T-cell leukemia/lymphoma: its close association with skin involvement and unfavorable outcome. Clin Cancer Res. 2003;9:3625-34.

12. Ohshima K. Molecular pathology of adult T-cell leukemia/lymphoma. Oncology. 2015;89:7-15.

13. Campuzano-Zuluaga G, Pimentel A, Chapman-Fredricks JR, et al. Differential CD30 expression in adult T-cell leukemia-lymphoma subtypes. Retrovirology. 2014;11:129.

14. Yamaguchi T, Ohshima K, Karube K, et al. Clinicopathological features of cutaneous lesions of adult T-cell leukaemia/ lymphoma. Br J Dermatol. 2005;152:76-81.

15. Takahashi K, Tanaka T, Fujita M, et al. Cutaneous-type adult T-cell leukemia/lymphoma. A unique clinical feature with monoclonal T-cell proliferation detected by Southern blot analysis. Arch Dermatol. 1988;124:399-404.

16. Dosaka N, Tanaka T, Miyachi Y, et al. Examination of HTLV-I integration in the skin lesions of various types of adult $\mathrm{T}$-cell leukemia (ATL): independence of cutaneous-type ATL confirmed by Southern blot analysis. J Invest Dermatol. 1991;96:196-200.

17. Fujihara K, Goldman B, Oseroff AR, et al. HTLV-associated diseases: human retroviral infection and cutaneous T-cell lymphomas. Immunol Invest. 1997;26:231-42.

18. Bittencourt AL, Oliveira PD, Andrade AC, et al. Analysis of cutaneous lymphomas in a medical center in Bahia, Brazil. Am J Clin Pathol. 2013;140:348-54.

19. Johno M, Ono T. [Clinicopathological differential diagnosis of mycosis fungoides/Sezary syndrome from the cutaneous type of adult T-cell leukemia/lymphoma]. Nihon Rinsho. 2000;58:660-4.

20. Bangham CR, Toulza F. Adult T cell leukemia/lymphoma: FoxP3 $(+)$ cells and the cell-mediated immune response to HTLV-1. Adv Cancer Res. 2011;111:163-82.

21. Satou A, Asano N, Kato S, et al. FoxP3-positive T cell lymphoma arising in non-HTLV1 carrier: clinicopathological analysis of 11 cases of PTCL-NOS and 2 cases of mycosis fungoides. Histopathology. 2016;68:1099-108. 
22. Ito $\mathrm{M}$, Zhao $\mathrm{N}$, Zeng $\mathrm{Z}$, et al. Interleukin-2 functions in anaplastic large cell lymphoma cells through augmentation of extracellular signal-regulated kinases $1 / 2$ activation. Int $\mathbf{J}$ Biomed Sci. 2011;7:181-90.

23. Gjerdrum LM, Woetmann A, Odum N, et al. FOXP3 positive regulatory T-cells in cutaneous and systemic CD30 positive T-cell lymphoproliferations. Eur J Haematol. 2008;80:483-9.

24. Asano N, Suzuki R, Ohshima K, et al. Linkage of expression of chemokine receptors (CXCR3 and CCR4) and cytotoxic molecules in peripheral $\mathrm{T}$ cell lymphoma, not otherwise specified and ALK-negative anaplastic large cell lymphoma. Int $\mathbf{J}$ Hematol. 2010;91:426-35.

25. Takeshita M, Akamatsu M, Ohshima K, et al. CD30 (Ki-1) expression in adult T-cell leukaemia/lymphoma is associated with distinctive immunohistological and clinical characteristics. Histopathology. 1995;26:539-46.
26. Takeshita M, Ohshima K, Akamatsu M, et al. CD30-positive anaplastic large cell lymphoma in a human T-cell lymphotropic virus-I endemic area. Hum Pathol. 1995;26:614-9.

27. Takimoto $\mathrm{Y}$, Tanaka $\mathrm{H}$, Tanabe $\mathrm{O}$, et al. A patient with anaplastic large cell lymphoma (Ki-1 lymphoma) showing clonal integration of HTLV-1 proviral DNA. Leukemia. 1994;8:507-9.

28. Ohtsubo H, Arima N, Matsushita K, et al. Human T lymphotropic virus-type I Tax induction of CD21/Epstein-Barr virus receptor expression on $\mathrm{T}$ cells and its significance in leukemogenesis of adult T cell leukemia. Exp Hematol. 1997;25:1246-52.

29. Akamatsu M, Takeshita M, Ohshima K, et al. Analysis of adhesion molecules in Ki-1 anaplastic large-cell lymphoma. Virchows Arch. 1994;425:33-9.

30. Chen X, Cherian S. Immunophenotypic characterization of Tcell prolymphocytic leukemia. Am J Clin Pathol. 2013;140:727-35 